\title{
Adapting a corporate entrepreneurship assessment instrument for Romania
}

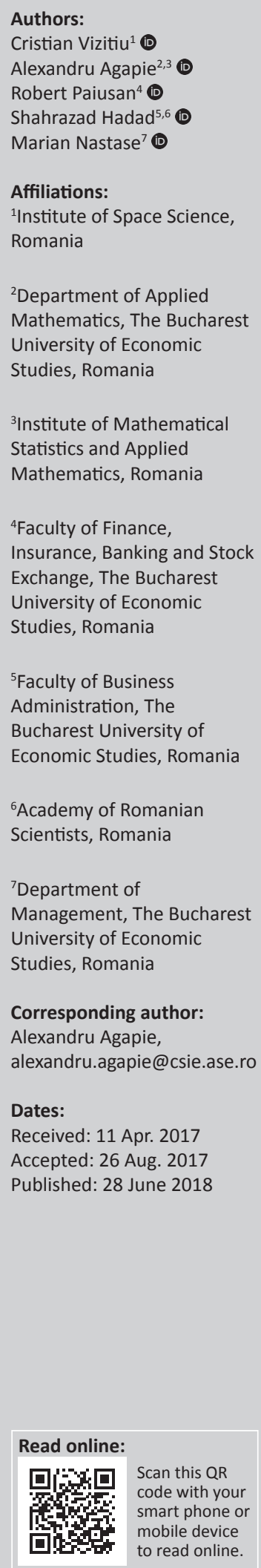

Background: The study adapts the corporate entrepreneurship assessment instrument (CEAI), a notable North American psychometric instrument used to evaluate entrepreneurial culture, and investigates its construct validity scale, taking into account that psychometric instruments have limited cross-cultural portability.

Objectives: We aim at identifying the perceived internal management key factors in the Romanian entrepreneurial culture (private sector) and applying CEAI to emergent economies.

Method: The corporate entrepreneurship assessment instrument uses a 48-item Likert scale questionnaire to collect information from a large sample of employees working in different companies. The questions, seen as random variables, are then factor analysed in order to get a reduced more manageable structure. Factors are finally interpreted with respect to the entrepreneurial propensity of the business sector in study. The software used for statistical analysis was SPSS.

Results: The survey conducted on 175 professionals from Romanian technology-based companies yielded a 10-factor structure for this particular business environment: reinforcement and work discretion, dynamic environment and decreased formalisation, delegation, time availability, strategic awareness, management support, stress, vertical communication, horizontal communication and knowledge sharing.

Conclusion: The study provides a thorough understanding of the Romanian post-communist corporate culture, and, together with a similar analysis recently performed in South Africa, aims to create a clearer picture of cross-cultural portability of entrepreneurship psychometric instruments.

\section{General framework}

Highlighting the factors that contribute to the economic development of private-owned enterprises has preoccupied scholars for more than two centuries. From among these factors, Smith emphasised the division of work, Ricardo the revenues of production factors and Keynes the marginal inclination towards investments.

Schumpeter has significantly contributed to the motives and questions pertaining to transformation, and from a historical perspective, to the survival of the free enterprise system. The underlying assumptions of his theory require the understanding of the role of the entrepreneur.

Generally speaking, any person with economic initiatives can claim to be an entrepreneur. However, as it has been pointed out, only the market economy environment allows the entrepreneur to be the promoter of innovation in various fields of activity with respect to products, services, organisational processes, resources and markets (Swedberg 2007). This idea is known in the literature as the Schumpeterian theory - 'new combinations that may dramatically alter the bases of competition in an industry, or lead to the creation of a new industry' (Sharma \& Chrisman 1999:18), or embodied in incremental improvements and diversifications on the current markets (Vizitiu 2014). Miller (1983) presented corporate entrepreneurship (CE) as the capability of the company to innovate new products and services, to be proactive by bringing newness on the market and to take risks getting involved in technology-based ventures with high uncertainty. On the contrary, other authors sustained that CE comprises four directions: sustained regeneration - equivalent with continuous improvement of the products on current or similar markets; corporate rejuvenation - requiring the restructuring of internal resources and

How to cite this article: Vizitiu, C., Agapie, A., Paiusan, R., Hadad, S. \& Nastase, M., 2018, 'Adapting a corporate entrepreneurship assessment instrument for Romania', South African Journal of Business Management 49(1), a8. https://doi.org/10.4102/sajbm.v49i1.8 Copyright: @ 2018. The Authors. Licensee: AOSIS. This work is licensed under the Creative Commons Attribution License. 
capabilities; strategic renewals - regarding the company relationship between different markets; redefinition of the industry domain - targeting radical innovations and industry disequilibrium (Frederiksen \& Davies 2008).

Concerning the size and form of ownership of innovative enterprises, Schumpeter started a debate that lasted for over a century. He differentiated between owner-operated enterprises and managers-operated (other than the owners-) enterprises. Moreover, he asserted that large enterprises, active on strong and aggressive monopolistic markets in search of big profits, are more innovative than small enterprises, active on competitive markets. The technical progress is thus bureaucratised because the decision-makers are now the increasingly opportunistic managers and not the owners themselves. Under these circumstances, the innovation process becomes a quasi-automatic process that no longer needs a dynamic entrepreneur. The Schumpeterian hypothesis, as it is known in the literature, was partially or totally rejected by Arrow and others, who claimed that all enterprises are interested in favouring the innovative process. Drucker, who in his early years took part in the Kapitalismusdebatte (debate on the future of capitalism) in Europe, described the organisational extent of the free enterprise as being 'receptive to innovation and willing to perceive change as an opportunity rather than a threat' (Drucker 1985:150).

The scholars' effort to determine the perceived internal factors for entrepreneurial activities was aimed to create psychometric instruments able to diagnose the level of entrepreneurial behaviour and culture within existing organisations.

Adapting Schumpeter's and other scholars' ideas to contemporary developments, processes and phenomena, the recent literature on $\mathrm{CE}$ emphasises that as globalisation and technological developments have accelerated (Vizitiu 2014), companies were forced to heavily rely on diversified information to create innovations (Dumitrache \& RăileanuSzeles 2014), and implicitly, to gain sustainable competitive advantage in order to survive and grow. Thus, the phenomenon of entrepreneurship within existing companies (Antoncic \& Hisrich 2001) emerged in the same way as individual entrepreneurship, but directed towards already established companies. It includes specific attitudes of employees and tendencies of companies of all sizes to prosper in their specific competitive environments (Kuratko 2009). The present business environment requires entrepreneurial strategies for the established companies to succeed; consequently, the CE strategy distinguishes itself from other entrepreneurial unplanned and spontaneous initiatives (Burgelman 1983) through its specific goal defined as 'a vision-directed, organization-wide reliance on entrepreneurial behaviour that purposefully and continuously rejuvenates the organization and shapes the scope of its operations through the recognition and exploitation of entrepreneurial opportunity' (Ireland, Covin \& Kuratko 2009:21).
Even if currently there is no universally accepted definition of CE (Gautam \& Verma 1997; Sharma \& Chrisman 1999) and the phrase corporate entrepreneurship may sound as an oxymoron because of the association of the bureaucratic and hostile environment of large companies to innovative and creative attitudes given by the entrepreneurship concept, CE represents a viable solution of already established companies to systematically pursue technological opportunities requiring considerable long-term capital investments with important societal benefits through the development of new products and markets (Sathe 2003).

One of the most comprehensive and enlightened structure of the CE strategy analyses four main components (Thornberry 2001):

- Corporate venturing, which 'means that the firm will enter new businesses by expanding operations in existing or new markets' (Zahra 1995:227), involving new competencies and learning attitudes for employees.

- Intrapreneuring, which is oriented to entrepreneurial behaviours of employees seen as 'the dreamers who figure out how to turn an idea into a profitable reality' (Pinchot 1985:ix).

- Organisational transformation given by rearrangement of resources within companies in a new pattern in order to gain new capabilities and pursue new business opportunities without resorting to downsizing, reengineering or cost-cutting transformations.

- Industry rule-bending with respect to altering the rules of competitiveness by achieving the highest operational efficiency among rivals.

The present research undertakes an empirical identification of organisational factors within the private sector to foster entrepreneurship in existing Romanian organisations, with the final goal of creating a diagnosis CE psychometric instrument for the national business culture.

As a critical affirmation to the relevant corpus, the limitations of current literature on internal factors that promote $\mathrm{CE}$ have to be underlined. Even if the factors are numerous and well explained - see, for example the seminal paper of Kuratko, Montagno and Hornsby (1990) literature fails to provide an accurate management model for promoting $\mathrm{CE}$ activities, and implicitly, to foster the creation, identification and proper exploitation of business opportunities. The lack of guidance on the managers' role in CE engagement was firstly pointed out by Hornsby, Kuratko and Zahra (2002).

Since the second half of 20th century, many psychometric instruments have emerged, with the purpose of diagnosing the level of entrepreneurship within internal organisational climate. In this context, Hornsby et al. (2002) developed one of the most popular psychometric instruments, called corporate entrepreneurship assessment instrument (CEAI), for the assessment of entrepreneurial organisational climates in the North American culture. 
The present research aims at developing a specific CE instrument for the Romanian business culture, starting from the original North American CEAI, investigating its construct validity and then successively tailoring it, similar to the way Van Wyck and Adonisi (2011) developed their own CEAI for the South African entrepreneurial culture.

Given that CEAI was reconfigured and tested in time, it is noteworthy that its traceability can be followed: in 1990 under the name of intrapreneurial assessment instrument, the model targeted factors such as management support for intrapreneurship, resource and reward availability, risk taking, time availability and organisational structure (Antoncic \& Hisrich 2001; Kuratko et al. 1990), but the empirical analysis performed at that time was not valid for all the five key factors considered (Hornsby et al. 2002). Corporate entrepreneurship assessment instrument, on the other hand, is envisaged to be able 'to gauge the organizational factors that foster corporate entrepreneurial activity within a company' (Hornsby et al. 2002:263), whereas it is based on other five key factors which successfully loaded on the 48 CEAI items for assessing the entrepreneurial North American culture. The five empirical key factors that represent the cornerstone for CEAI are the following: the dimension of the perception of top management support for encouraging the companies' employees to champion ideas; the dimension of the perception of work discretion with respect to tolerance of failure, responsibility, level of delegation and authority; the dimension of the perception of rewards and reinforcements with respect to risk taking and first mover behaviour; the dimension of the perception of time availability concerning time tolerance in performing job responsibilities; the dimension of the perception of organisational boundaries with respect to the information flow between departments and even organisations (Goodale et al. 2011).

Lau et al. (2012) performed a similar analysis on Hong Kong $\mathrm{CE}$ and developed an instrument called the entrepreneurial behaviour inventory (EBI). Using an original 'simulated incident method', yet under the same process of item reduction via factor analysis (FA), they identified four key entrepreneurial characteristics: innovativeness, risk taking, change orientation and opportunism.

Even if the need to study CE within emerging economies has been pointed out by Zahra, Van de Velde and Larraneta (2007) and Ahlstrom (2010), such research has not been conducted until recently, and only with respect to East Asian economies like India (Bhardwaj \& Sushil 2012). As there are plenty of contextual differences between developed and emerging markets, on one hand, and between East Asian and East European emerging markets, on the other hand, adapting CEAI to an East European, post-communist emerging economy like Romania, is worth being considered.

The research undertaken for this study has a twofold purpose. Firstly, it aims to contribute to international and Romanian strategic management by drawing a comparison between the
North American and Romanian entrepreneurial cultures. Secondly, at the same time, it aims to contribute to the already existent Romanian entrepreneurial practice environment (Craciun et al. 2015; Nastase \& Valimareanu 2017; Soare et al. 2017), by developing a tailored psychometric instrument for a Romanian CE diagnosis. This Romanian CE exploration by adapting an American psychometric instrument is undertaken because of some well-acknowledged reasons which are as follows: limited cross-cultural portability of psychometric instruments as stated in the literature of psychology; the potential of expanding entrepreneurial theories by investigating them in other cultures as stated by Antoncic and Hisrich (2001), Brislin (1980), De Klerk, Boshoff and Van Wyck (2009), and Van Wyck and Adonisi (2011); and last but not least, it is given even by the CEAI authors' plea in Hornsby, Holt and Kuratko (2008) and Hornsby et al. (2002) for a possible validation of their psychometric instrument scale in a cross-cultural context.

Because of the way in which individuals perceive their social and cultural milieu, they show certain forms of behaviour which influence at their turn activities of interpreting and responding to the questionnaires. Thus, these previously mentioned aspects constitute the reason of emerging possible problems with regard to equivalence and validation of psychometric instruments across cultures. It is worth noticing that a similar application of CEAI to the South African business environment has been performed in Wyck and Adonisi (2011) and had resulted in an eight-factor solution!

Taking into account the considerable contributions of CEAI to both the literature and the North American entrepreneurial culture, the need and opportunity becomes manifest to provide a considerable contribution to the Romanian private sector dealing with technologies for the space sector, and also for energy, medicine, transports and so on, through the present research by investigating CEAI construct validity, and implicitly, identifying those key factors that apply exclusively to the Romanian entrepreneurial and organisational culture.

The rationality of psychometric instruments cross-culture portability without modification is given by the anthropologists' explanation of the term culture which identifies patterns of understandings, attitudes and specific mental models which fully comply with the society the employees live in (Jahoda 2012; Kroeber \& Kluckholm 1952).

\section{Method and data}

Factor analysis - also referred to in statistics as principal component analysis (PCA) - is a clustering technique for large sets of variables, each cluster being defined by a central element, a factor. The emerging factors - the cardinal number of which is significantly lower than the number of initial variables - characterise the underlying process that correlates the variables (Tabachnick \& Fidell 2007:607). Rigorously, if $X_{i}$ are the $\mathrm{p}$ observed variables (measured for each of the $n$ subjects), $F_{i}$ are the $m$ factors, $a_{i j}$ are the so-called factor loadings and $e_{i}$ the errors associated with the variables, 
leading to equation 1 model (B. Habing [University of South Carolina] pers. comm., 15 October 2003).

$$
\begin{gathered}
X_{1}=a_{11} F_{1}+\ldots+a_{1 m} F_{m}+e_{1} \\
X_{2}=a_{21} F_{1}+\ldots+a_{2 m} F_{m}+e_{2} \\
\vdots \\
X_{p}=a_{p 1} F_{1}+\ldots+a_{p m} F_{m}+e_{p}
\end{gathered}
$$

The whole FA is centred on the correlation matrix R (equation 2), given by:

$R=A A^{T}+\operatorname{cov}(e)$

As for the number of extracted factors, it is reasonable to expect $\mathrm{m}<<$ p. In SPSS, for example (George \& Mallery 2003), one can either fix a priori the number of factors or leave this option to the programme. Usually the number of factors is determined by the eigenvalue criterion (B. Habing [University of South Carolina] pers. comm., 15 October 2003): check how many of the eigenvalues associated to matrix $R$ are larger than 1, and fix the number of factors accordingly. For a thorough discussion on this topic, the reader is referred to Hair et al. (1998:103) and Stevens (2002:389).

A second criterion, to be applied when deciding the number of factors, is to keep as many factors as required in order to explain at least $60 \%$ of the total variance within variables.

Sometimes, there is an urge to use an a priori number of factors. Similar studies performed in the United States (Hornsby et al. 2002), or South Africa (Van Wyck \& Adonisi 2011), for the same CE assessment instrument provided a number of five and eight factors, respectively. Nevertheless, the authors did not impose a fixed number of factors a priori, and they interpret the relatively large number of factors provided by their analysis (ten) as an effect of the young, emerging Romanian market.

The data were collected from Romanian companies, 175 subjects (104 women, 71 men) ranging from large companies to medium-sized and small enterprises from the private sector. Significant data on the subjects that filled in the questionnaire are provided in Figures 1-3.

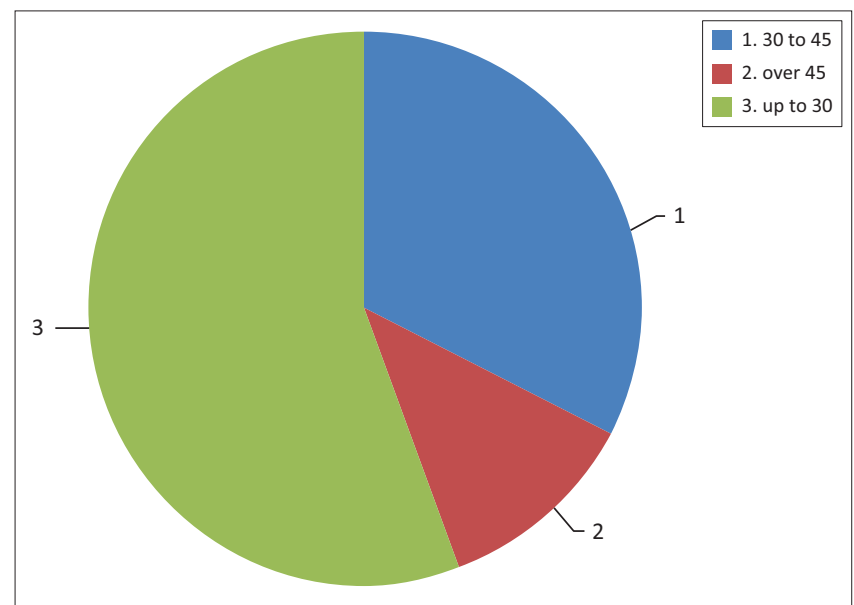

FIGURE 1: Age distribution of the subjects (years).

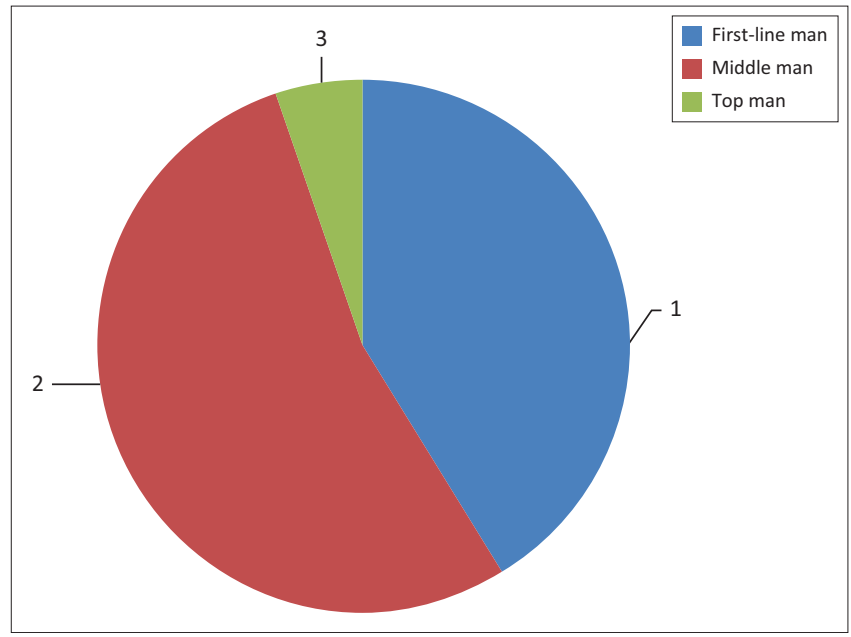

FIGURE 2: Position within the company.

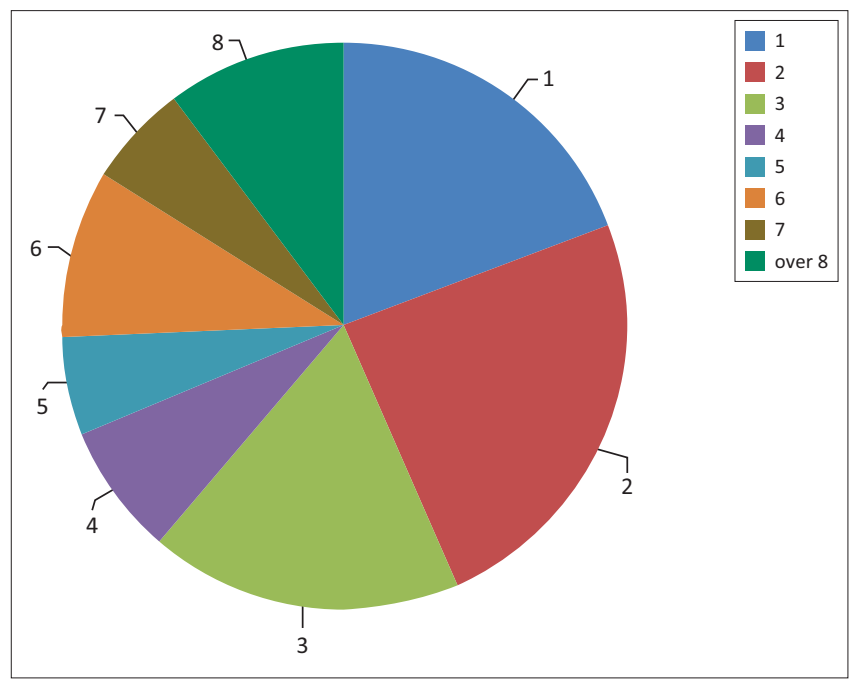

FIGURE 3: Experience within the company (years).

\section{Numerical results}

The practical question of this study is: What would the factor structure of the CEAI introduced by Hornsby et al. (2002) be when applied to a Romanian sample?

To answer this question, the authors performed an exploratory FA in SPSS, using an extraction method principal component, orthogonal varimax rotation with Kaiser normalisation, on the 48-item CEAI on a sample of $n=175$ employees from Romanian private companies.

Of the initial 48 variables (items), 13 exhibited eigenvalues larger than one. To improve consistency in the structure of the model, the factors carrying only one variable were excluded first. In a second stage, the variables with significant loads (i.e. larger than 0.45) on more than one factor were excluded. In a third stage, the 0.45 value was used as a minimal threshold for the whole set of loadings, so that variables with lower loadings were also excluded.

After the reduction phase, the number of variables decreased from 48 to 38 , while the number of factors was downsized to 11 . 
Each factor was checked for internal consistency using the Cronbach's alpha coefficient, and the only factors (and variables within: Q36, Q37, Q38) that were discarded were the ones below the minimal acceptance threshold of 0.5 (George \& Mallery 2003). This operation produced lead to reducing the set of variables down to 35 items. Table 1 shows the items per factor distribution, while Table 2 gathers the respective Cronbach's coefficients.

The ten factors of our analysis are interpreted qualitatively as: (1) reinforcement and work discretion; (2) dynamic environment and decreased formalisation; (3) delegation; (4) time availability; (5) strategic awareness; (6) management support; (7) stress; (8) vertical communication; (9) horizontal communication; and (10) knowledge sharing.

Box 1 shows the explicit factor-item distribution, using the qualitative interpretation of the factors.

The cumulative total variance explained by the ten factors was $63.83 \%$ - after subtracting the variance of the eliminated factor in Cronbach's coefficient test.

\section{Conclusions}

The present research targeted investigation on the CEAI construct validity with respect to the five-factor, 48-item structure, in order to empirically identify a tailored set of organisational factors and to implicitly shape a specific CE psychometric instrument exclusively tailored for the Romanian entrepreneurial culture of the private sector. As expected and as evidence of the psychology literature which severely questions the use of psychometric instruments across cultures without modifications, the present research conducted on a sample of 175 Romanian subjects in the private sector revealed a ten-factor structure which loaded on 35 items, different to the CEAI for the North American entrepreneurial culture which has five factors on 48 items.

The high factor loadings and the eligible Cronbach's alpha coefficients emphasise the fact that the 10-factor CEAI structure obtained for the Romanian entrepreneurial culture is statistically acceptable. On the other hand, the variety of the 10-factor structure, expressed through reinforcement and work discretion; dynamic environment and decreased formalisation; delegation; time availability; strategic awareness; management support; stress; vertical communication; horizontal communication; knowledge sharing, provides it with the capacity to be used in business practice.

The current research started from the CEAI authors' plea for verifying their psychometric instrument in other cultures, consolidating the hypothesis given by limited cross-culture portability of psychometric instruments, but also represents substantial contribution both for the Romanian entrepreneurial culture and for the international strategic management with regard to expanding the existing entrepreneurial theories through their applications in other cultures.

Hence, the present research proves the existence of ten stable internal key factors which encourage the entrepreneurial attitudes and behaviours within existing companies in the frame of Romanian private environment in order for the companies to embark on new ventures, strategic renewal and important innovations at all levels.

The ten factors resulting from the research, which correspond to the Romanian entrepreneurial culture could be described as follows: reinforcement and work discretion as the way employees are aware that, at the top management level, their beliefs and behaviour are encouraged; dynamic environment and decreased formalisation as the extent to which the organisation embraces new work-improving methods and stays up to date with obtaining high-quality products and services, and also refers to the employees' perception of the organisational procedures and rule stiffness; delegation, as being the extent to which employees perceive the company permissiveness with respect to the chance to authorise various persons to use their own judgement in the current business activities; time availability translated in the way employees perceive the correlation between the amount of

TABLE 1: Ten-factor solution.

\begin{tabular}{|c|c|c|c|c|c|c|c|c|c|}
\hline \multicolumn{2}{|c|}{ Factor 1} & \multicolumn{2}{|c|}{ Factor 2} & \multicolumn{2}{|c|}{ Factor 3} & \multicolumn{2}{|c|}{ Factor 4} & \multicolumn{2}{|c|}{ Factor 5} \\
\hline Item & Load & Item & Load & Item & Load & Item & Load & Item & Load \\
\hline Q11 & 0.533 & Q1 & 0.748 & Q19 & 0.549 & Q40 & 0.571 & Q10 & 0.718 \\
\hline Q24 & 0.600 & Q2 & 0.711 & Q26 & 0.625 & Q41 & 0.803 & Q18 & 0.612 \\
\hline Q29 & 0.753 & Q6 & 0.572 & Q27 & 0.714 & Q42 & 0.804 & Q48 & 0.647 \\
\hline Q30 & 0.781 & Q12 & 0.737 & Q28 & 0.720 & Q43 & 0.599 & - & - \\
\hline Q31 & 0.853 & - & - & - & - & - & - & - & - \\
\hline \multicolumn{2}{|c|}{ Factor 6} & \multicolumn{2}{|c|}{ Factor 7} & \multicolumn{2}{|c|}{ Factor 8} & \multicolumn{2}{|c|}{ Factor 9} & \multicolumn{2}{|c|}{ Factor 10} \\
\hline Item & Load & Item & Load & Item & Load & Item & Load & Item & Load \\
\hline Q9 & 0.681 & Q3 & 0.529 & Q34 & 0.677 & Q15 & 0.698 & Q17 & 0.582 \\
\hline Q14 & 0.499 & Q25 & 0.798 & Q35 & 0.688 & Q44 & 0.594 & Q22 & 0.582 \\
\hline Q16 & 0.483 & Q39 & 0.513 & Q47 & 0.580 & - & - & Q23 & 0.719 \\
\hline
\end{tabular}

TABLE 2: Cronbach's alpha coefficients.

\begin{tabular}{lccccccccccc}
\hline Factor & $\mathbf{1}$ & $\mathbf{2}$ & $\mathbf{3}$ & $\mathbf{4}$ & $\mathbf{5}$ & $\mathbf{6}$ & $\mathbf{7}$ & $\mathbf{8}$ & $\mathbf{9}$ & $\mathbf{1 0}$ \\
\hline Cronbach's coefficient & 0.867 & 0.793 & 0.824 & 0.694 & 0.535 & 0.596 & 0.538 & 0.587 & 0.575 & 0.687 \\
\hline
\end{tabular}


BOX 1: Qualitative description of the ten factors.

\section{Factor 1: Reinforcement and work discretion}

1. Senior managers encourage innovators to bend rules and rigid procedures in order to keep promising ideas on track.

2. I feel that I am my own boss and do not have to double check all of my decisions.

3. I have the freedom to decide what I do on my job.

4. It is basically my own responsibility to decide how my job gets done.

5. I almost always get to decide what I do on my job.

6 . I have much autonomy on my job and am left on my own to do my work.

Factor 2: Dynamic environment and decreased formalisation

1. My organisation is quick to use improved work methods.

2. My organisation is quick to use improved work methods that are developed by employees.

3. The development of new and innovative ideas is usually followed by a promotion.

4. Many top managers are known for their experience with the innovation process.
prony top

Factor 3: Delegation

1. The term 'risk taker' is considered a positive attribute for people in my work environment.

2. This organisation provides the opportunity to be creative and try my own

methods of doing the job.

3. This organisation provides freedom to use my own judgement.

4. This organisation provides opportunities to use my skills and abilities.

Factor 4: Time availability

1. During the past 3 months, my work load was too heavy to have time to develop new ideas.

2. I always seem to have plenty of time to get everything done.

3 . I have just the right amount of time and work load to do everything well.

4. I feel that I am always working with time constraints on my job.

Factor 5: Strategic awareness

1. On my job, I know exactly what is expected of me.

2. My job description clearly specifies the standards of performance on which

my job is evaluated.

3. I clearly know what level of work performance is expected of me in terms of amount, quality and timelines of output.

Factor 6: Management support

1. The 'doers' are allowed to make decisions on projects without going through elaborate justification and approval procedures.

2. Employees with successful innovative projects receive additional reward and compensation for their ideas and efforts beyond the standard reward system.

3. Individual risk takers are often rewarded for their willingness to champion new projects, whether eventually successful or not.

Factor 7: Stress

1. My job is structured so that I have very little time to think about wider organisational problems.

2. Harsh criticism and punishment result from mistakes made on the job.

3. There is a lot of challenge in my job.

Factor 8: Vertical communication

1. My manager helps me get my work done by removing obstacles.

2. The rewards I receive are related to my work on the job.

3. During the past year, my immediate supervisor frequently discussed my work performance with me.

Factor 9: Horizontal communication

1. Within the organisation, there are several options for employees to get financial support for their innovative projects and ideas.

2. My co-workers and I always find time for long-term problem-solving.

Factor 10: Knowledge sharing

1. People are often encouraged to take calculated risks with new ideas around here.

2. There is considerable drive among people in the organisation to generate new ideas without concern for crossing departmental or functional boundaries.

3. In this organisation, employees are encouraged to talk to colleagues in other departments about ideas for new projects.

work to be done and the time allocated by the organisation; strategic awareness, as the extent to which employees are aware of the company's vision and mission and of their potential contribution to those strategic aspects; management support illustrated through the way the top management's permissiveness with respect to championing ideas and the corresponding resources allocated is perceived; stress, as the extent to which the pressure at work caused by multiple deadlines, criticism and job challenges is perceived; vertical communication, as the extent to which employees perceive the communication between different top-down and bottom-up levels; horizontal communication, with respect to communication between different departments and even partner organisations at the same management levels; knowledge sharing in terms of knowledge dynamics and homogenisation through formal and informal networking.
The study not only presents an outstanding contribution for the Romanian entrepreneurial culture in the private sector for diagnosing the level of entrepreneurship inside organisations through the adapted and validated CEAI psychometric instrument but also for international strategic management, as it provides an interesting comparison between the North American and Romanian entrepreneurial cultures.

In Romania, this kind of research is the first attempt based on the authors' expertise of adapting an important psychometric instrument to Romania, another culture than the one where the psychometric instrument was developed in the first place. Moreover, it provides an opportunity for future research to develop a confirmatory analysis to make available the validation of the comprehensive image presented in the current article. Consequently, the resulting diagnosis psychometric instrument corresponding exclusively to the Romanian entrepreneurial culture of the private sector represents an important tool for Romanian top management to identify the organisational needs with respect to enabling the internal entrepreneurial behaviour and to preparing training programmes accordingly in order to break the status quo and embrace the CE benefits, thus gaining sustainable competitive edge.

\section{Acknowledgements}

During the revising stages, this work has been partially supported by the Academy of Romanian Scientists, Program No. 15/2018 'Strategies for Implementing Knowledge Economy in Romania'.

\section{Competing interests}

The authors declare that they have no financial or personal relationships which may have inappropriately influenced them in writing this article.

\section{Authors' contributions}

C.V. contributed to the theoretical framework and data analysis, discussed the results and commented on the manuscript. A.A. contributed to the method design, data processing and analysis; discussed the results and commented on the manuscript. R.P. contributed to the theoretical framework, discussed the results and commented on the manuscript. S.H. contributed to the conclusions, discussed the results, commented on the manuscript and proofread the manuscript. M.N. contributed to the theoretical framework, discussed the results and commented on the manuscript.

\section{References}

Ahlstrom, D., 2010, 'Innovation and growth: How business contributes to society' Academy of Management Perspectives 24(3), 10-23. https://doi.org/10.5465/ AMP.2010.52842948

Antoncic, B. \& Hisrich, R.D., 2001, 'Intrapreneurship: Construct refinement and crosscultural validation', Journal of Business Venturing 16(5), 495-527. https://doi. org/10.1016/S0883-9026(99)00054-3

Bhardwaj, B.R. \& Sushil, 2012, 'Internal environment for corporate entrepreneurship: Assessing CEAl model for emerging economies', Journal of Chinese Entrepreneurship $4(1), 70-87$. 
Brislin, R.W., 1980, Handbook of crosscultural psychology, Allyn \& Bacon, Boston, MA.

Burgelman, R.A., 1983, 'Corporate entrepreneurship and strategic management: Insights from a process study', Management Science 29(12), 1349-1364. https:// doi.org $/ 10.1287 / \mathrm{mnsc}$.29.12.1349

Craciun, L., Nastase, M., Stamule, T. \& Vizitiu, C., 2015, 'Leadership in Romanian smal to medium enterprises', Sustainability 7, 4183-4198.

De Klerk, M., Boshoff, A. \& Van Wyk, R., 2009, 'Measuring meaning in life in South Africa: Validation of an instrument developed in the USA', South African Journal of Psychology 39(3), 314-325. https://doi.org/10.1177/008124630903900306

Drucker, P.F., 1985, Innovation and entrepreneurship, Harper \& Row Publishers, New York.

Dumitrache, V. \& Raileanu-Szeles, M., 2014, 'The role of business education provided through lifelong learning in enhancing professional competencies: Evidence from the Eu-27 Dataset', Amfiteatru Economic 16(37), 874-874.

Frederiksen, L. \& Davies, A., 2008, 'Vanguards and ventures: Projects as vehicles for corporate entrepreneurship', International Journal of Project Management 26(2), 487-496. https://doi.org/10.1016/j.ijproman.2008.05.006

Gautam, V. \& Verma, V., 1997, 'Corporate entrepreneurship: Changing perspectives' The Journal of Entrepreneurship 6(2), 233-247. https://doi.org/10.1177/0971355 79700600207

George, D. \& Mallery, P., 2003, SPSS for windows step by step: A simple guide and reference, 4th edn., Allyn \& Bacon, Boston, MA.

Goodale, J.C., Kuratko, D.F., Hornsby, J.S. \& Covin, J.G., 2011, 'Operations management and corporate entrepreneurship: The moderating effect of operations control on the antecedents of corporate entrepreneurial activity in relation to innovation performance', Journal of Operations Management 29, 116-127. https://doi.org/ 10.1016/j.jom.2010.07.005

Habing, B., 2003, 'Exploratory factor analysis', Personal communication, 15 October University of South Carolina, viewed 10 March 2017, from http://people.stat.sc. edu/habing/courses/530EFA.pdf

Hair, J.F. Jr., Anderson, R.E., Tatham, R.L. \& Black, W.C., 1998, Multivariate data analysis, 5th edn., Prentice Hall, Upper Saddle River, NJ.

Hornsby, J.S., Holt, D.T. \& Kuratko, D.F., 2008, 'The dynamic nature of corporate entrepreneurship: Assessing the CEAl', in Academy of Management Proceedings, Anaheim, CA, August 8-13, pp. 1-6.

Hornsby, J.S., Kuratko, D.F. \& Zahra, S.A., 2002, 'Middle managers' perception of the internal environment for corporate entrepreneurship: Assessing a measurement scale', Journal of Business Venturing 17(3), 253-273. https://doi.org/10.1016/ S0883-9026(00)00059-8

Ireland, R.D., Covin, J.G. \& Kuratko, D.F., 2009. 'Conceptualizing corporate entrepreneurship strategy', Entrepreneurship Theory and Practice 33(1), 19-46. https://doi.org/10.1111/j.1540-6520.2008.00279.x

Jahoda, G., 2012, 'Critical reflections on some recent definitions of "culture"', Culture Psychology 18(3), 289-303. https://doi.org/10.1177/1354067X12446229

Kroeber, T. \& Kluckholm, C., 1952, Culture: A critical review of concepts and definitions, Papers of The Peabody Museum, Harvard University, Cambridge, MA.
Kuratko, D.F., 2009, 'The entrepreneurial imperative of the 21st century', Business Horizons 52(5), 421-428. https://doi.org/10.1016/j.bushor.2009.04.006

Kuratko, D.F., Montagno, R.V. \& Hornsby, J.S., 1990, 'Developing an intrapreneurial assessment instrument for an effective corporate entrepreneurial environment', Strategic Management Journal 11(special issue), 49-58.

Lau, T.L.M., Shaffer, M.A., Chan, K.F. \& Man, T.W.Y., 2012, 'The entrepreneurial behaviour inventory: A simulated incident method to assess corporate entrepreneurship', International Journal of Entrepreneurial Behavior \& Research 18(6), 673-696. https://doi.org/10.1108/13552551211268120

Miller, D., 1983, 'The correlates of entrepreneurship in three types of firms', Management Science 29(3), 770-791. https://doi.org/10.1287/mnsc.29.7.770

Nastase, M. \& Valimareanu, I., 2017, 'Building a strong organizational culture for sustainable development of tourism companies', Review of Internationa Comparative Management 18, 122-130.

Pinchot, G. III, 1985, Intrapreneuring, Harper \& Row, New York.

Sathe, V., 2003, Corporate entrepreneurship: Top managers and new business creation, Cambridge University Press, New York. https://doi.org/10.1017/CBO9780511488719

Sharma, P. \& Chrisman, J.J., 1999, 'Toward a reconciliation of the definitional issues in the field of corporate entrepreneurship', Entrepreneurship: Theory and Practice 23(3), 11-27. https://doi.org/10.1177/104225879902300302

Soare, I., Cristache, N., Dobrea, C.R. \& Nastase, M., 2017, 'The rural touristic entrepreneurship - New opportunities of capitalizing the rural tourist potential in the context of durable development', European Journal of Sustainable Development 6, 231-252.

Stevens, J., 2002, Applied multivariate statistics for the social sciences, 4th ed., Lawrence Erlbaum, Mahwah, NJ.

Swedberg, R., 2007, 'Rebuilding Schumpeter's theory of entrepreneurship', in Conference on Marshall, Schumpeter and Social Science, pp. 1-28, Hitotsubashi University, Tokyo, Japan, March 17-18.

Tabachnick, B.G. \& Fidell, L.S., 2007, Using multivariate statistics, 5th edn., Pearson, Boston, MA.

Thornberry, N., 2001, 'Corporate entrepreneurship: Antidote or oxymoron?', European Management Journal 19(5), 526-533. https://doi.org/10.1016/S02632373(01)00066-4

Van Wyck, R. \& Adonisi, M., 2011, 'An eight-factor solution for the corporate entrepreneurship assessment instrument', African Journal of Business Management 5(8), 3047-3055.

Vizitiu, C., 2014, 'Conceptual diagnosis model based on distinct knowledge dyads for interdisciplinary environments', Management Dynamics in the Knowledge Economy 2(1), 71-86.

Zahra, S.A., 1995, 'Corporate entrepreneurship and financial performance: The case of management leveraged buyouts', Journal of Business Venturing 10(3), 225-247. https://doi.org/10.1016/0883-9026(94)00024-O

Zahra, S.A., Van de Velde, E. \& Larraneta, B., 2007, 'Knowledge conversion capability and the performance of corporate and university spin-offs', Industrial and Corporate Change 16(4), 569-608. https://doi.org/10.1093/icc/dtm018 